syringe. Unless the dose is expressed in terms of the volume of solution to be administered a calculation must be performed to convert the cose into a volume. This process is time consuming, and likely to result in errors. Such errors are made more likely by the stress of treating a cardiac arrest and the infrequency of cardiac arrest in children. It therefore seems reasonable to record the required volumes of drugs to be administered in such circumstances in a reference chart. This study has shown that such a chart signifi- cantly improves the speed and accuracy of determining the volumes of drugs to be administered when compared with the standard chart now in use.

We thank Dr Roger Flinn for his help and advice and Miss Cindy Billingham, senior information officer, West Midlands Regional Health Authority, for performing statistical analyses.

1 Oakley PA. Inaccuracy and delay in decision making in paediatric resuscitation and a proposed reference chart to reduce error. BMF 1988;297:817-9.

\title{
Treatment of acute mountain sickness by simulated descent: a randomised controlled trial
}

\author{
Peter Bärtsch, Beata Merki, Doris Hofstetter, Marco Maggiorini, Bengt Kayser, Oswald Oelz
}

Department of Sports Medicine, University Clinic of Medicine, D-6900 Heidelberg, Germany Peter Bärtsch, professor of sports medicine Beata Merki, research associate Doris Hofstetter, research associate

\section{Department of Medicine, University Hospital, CN-8091 Zurich, Switzerland \\ Marco Maggiorini, senior house officer \\ Oswald Oelz, professor of medicine}

Department of Physiology, University of Geneva, CH-1211 Geneva,

Switzerland

Bengt Kayser, research fellow

Correspondence to: Dr Bärtsch, Medizinische Universitätsklinik, Abteilung für Sportmedizin, Hospitalstrasse 3, D-6900 Heidelberg 1, Germany.

\section{Abstract}

Objective-To evaluate the therapeutic efficacy of a portable hyperbaric chamber for treatment of acute mountain sickness.

Design-Controlled randomised trial over two mountaineering seasons.

Setting-High altitude research laboratory at $4559 \mathrm{~m}$ above sea level.

Subjects-64 climbers with acute mountain sickness randomly allocated to different treatments.

Interventions-One hour of treatment in the hyperbaric chamber at a pressure of 193 mbar or 20 mbar as control or bed rest.

Main outcome measures-Symptoms of acute mountain sickness before, immediately after, and 12 hours after treatment. Permitted intake of analgesic and antiemetic drugs in the follow up period.

Results-Treatment with 193 mbar caused greater relief of symptoms than did control treatment or bed rest. During the 12 hour follow up period intake of analgesics was similar $(58-80 \%$ of subjects in each group). Symptom scores had improved in all subjects after 12 hours with no significant differences between groups.

Conclusions-One hour of treatment with 193 mbar in a portable hyperbaric chamber, corresponding to a descent of $2250 \mathrm{~m}$, leads to a short term improvement in symptoms of acute mountain sickness but has no beneficial long term effects attributable to pressurisation.

\section{Introduction}

About half the Himalayan trekkers examined at an altitude of $4240 \mathrm{~m}$ suffered from headache and at least one additional symptom of acute mountain sickness such as nausea, insomnia, or dizziness. ${ }^{1}$ Likewise the prevalence of acute mountain sickness in the Alps was found to be $9 \%, 18 \%, 27 \%$, and $51 \%$ at $2800 \mathrm{~m}$, $3050 \mathrm{~m}, 3600 \mathrm{~m}$, and $4500 \mathrm{~m}$ respectively. ${ }^{2}$ Severe acute mountain sickness with general malaise, headache resistant to analgesics, and vomiting may progress to cerebral and pulmonary oedema. ${ }^{34}$ The incidence of these life threatening conditions was estimated to be $2-3 \%$ in a trekking population in Nepal at $4240 \mathrm{~m}^{1}$ and $10 \%$ after rapid ascent to $4559 \mathrm{~m}$ in the Alps. ${ }^{5}$

As a common pathogenesis of high altitude illnesses has been suggested ${ }^{34}$ early successful treatment of acute mountain sickness may prevent the development of high altitude cerebral oedema or pulmonary oedema. Rapid descent, however, the treatment of choice, is often not possible while trekking for topographical reasons or while mountaineering because of adverse weather conditions or difficult terrain. Bottled oxygen is rarely carried by trekking or mountaineering parties as it is heavy and a limited supply provides only short term relief for a seriously ill mountaineer. Recently fabric hyperbaric chambers have been developed which allow the exposure of a person to 140-220 mbar above the ambient pressure by operating foot or hand driven pumps, thus simulating a descent of $1500-2500 \mathrm{~m}$ depending on the altitude and the type of bag used. ${ }^{\circ}$ The whole equipment, including the pump, weighs 4$6 \mathrm{~kg}$ and represents an inexhaustible device for rapid improvement of oxygenation.

Rapid relief of symptoms of acute mountain sickness and high altitude pulmonary oedema and cerebral oedema has been reported by investigators using these portable hyperbaric chambers. ${ }^{7.9}$ These uncontrolled studies, however, do not allow the assessment of long term effects of such treatment because they included only a small number of subjects and additional treatment such as supplemental oxygen, descent, or dexamethasone was used. We investigated the effect of 1 hour of hyperbaric treatment during a 12 hour follow up in 35 subjects with acute mountain sickness at $4559 \mathrm{~m}$ randomly allocated to pressurisation of 193 or 23 mbar. Because of unexpected beneficial effects with the control treatment ( 23 mbar) the next year another 36 subjects were randomly allocated to a treatment with 193 mbar, 16 mbar, or bed rest.

\section{Subjects and methods}

LOCATION AND SUBJECTS

The study was carried out at the high altitude research laboratory in the Capanna "Regina Margherita" located at an altitude of $4559 \mathrm{~m}$ (barometric pressure $430-440 \mathrm{~mm} \mathrm{Hg}$ ) in the Alps Valais. Subjects were recruited from mountaineers who happened to spend a night in this alpine hut while climbing in the mountains of the Monte Rosa. Mountaineers who had ascended by foot and who stayed at $4559 \mathrm{~m}$ for at least 12 hours after treatment were eligible to enter the trial if they suffered from headache and one or more additional symptoms of acute mountain sickness. Subjects with clinical signs of high altitude pulmonary oedema (dyspnoea at rest, respiration rate $>25 / \mathrm{min}$, and rales) and those who had taken acetazolamide or nifedipine during ascent were excluded from the study. Subjects were informed that different pressures were being tested, and throughout the study they were not aware of what pressures had been applied.

\section{STUDY DESIGN}

After informed consent subjects were randomly assigned to the various treatments. Randomisation was performed in blocks of six (in 1990) and nine (in 1991). When subjects agreed to participate in the trial the 
investigator assigned the treatment by drawing a lot from an envelope containing the assignments of one block. When the remaining lots could be predicted they were added to the envelope containing the next randomisation block. Treatment was instigated immediately after randomisation. In 1990,18 (13 in 1991) subjects were treated with maximum pressure and 10 (13 in 1991) subjects were treated with minimum pressure over 1 hour. Rest at the ambient pressure in the supine position outside the bag, introduced as a third treatment group in 1991, was assigned to 10 subjects. The protocol of the study was approved by the ethical committee of the University Hospital, Zurich.

Subjects underwent a clinical examination and filled out a questionnaire on their symptoms before, immediately after, and 12 hours after treatment. Arterial oxygen saturation was measured by a pulse oximeter (Biox 3700; Ohmeda, Denver) by using an ear probe for 15 minutes immediately before and 12 hours after treatment in subjects resting in a supine position. Oxygen saturation was also continuously monitored during treatment. Median values for each observation period were calculated by using the Profox software (Ohmeda, Denver). After treatment subjects were allowed to take analgesics (paracetamol) or antiemetics (thiethylperazine), and the intake was registered.

\section{PRESSURISATION}

A fabric hyperbaric chamber made by Certec (F-69210 Sourcieux-les-Mines, France) was used (figure). Pressurisation is achieved by a handpump moving 4 litres of air with each complete stroke. In this investigation pressure was supplied by an electrically driven compressor, and the air flow was controlled by a flowmeter. A high air flow of $40-50 \mathrm{1} / \mathrm{min}$ is recommended to keep the concentration of carbon dioxide inside the bag below $1 \%{ }^{6}$

Pressure during treatment was regulated by the adjustable outlet at 193 mbar (equivalent to a descent of $2250 \mathrm{~m}$ ) at a flow of $50 \mathrm{l} / \mathrm{min}$ in both years. The pressure was controlled by an altimeter (Thommen, Waldenburg, Switzerland) and built up or released within about 5 minutes. Preliminary trials and measurements of carbon dioxide tension with a 278 blood gas analyser (Ciba Corning Diagnosis AG, Dietlikon, Switzerland) in air sampled with syringes at the bottom of the bag above the head of the subject before the pressure was released had confirmed that the tension inside the bag was below $1 \%$ with an air flow of $50 \mathrm{l} / \mathrm{min}$.

The minimum pressure for the control treatment was determined by the air flow at maximum opening of

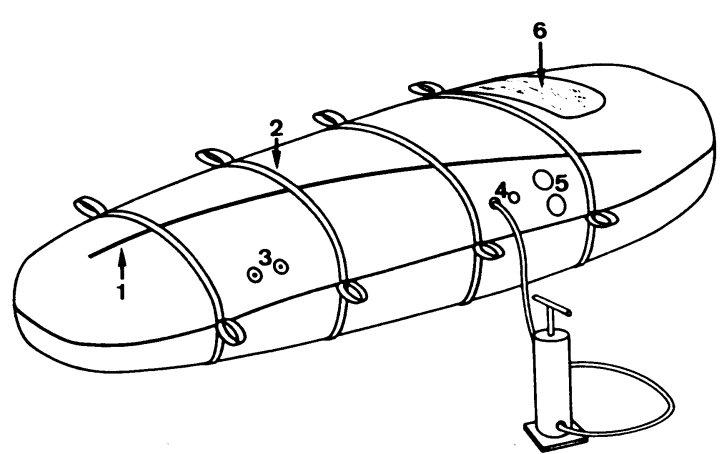

Fabric hyperbaric chamber $(230 \mathrm{~cm}$ long, average diameter $65 \mathrm{~cm})$ with hand pump which moves 4 litres of air with each complete stroke. $1=$ Zipper; 2 =safety strap with loops attached to carry bag; $3=$ valves that open at pressure of 200 mbar inside bag (two valves for reasons of safety); 4=two inlets/outlets with taps (in present study one inlet used for pressurisation, other device used as outlet, regulating pressure inside bag with tap); 5=two pouches with windows (one holds built in manometer, other used to hold altimeter $) ; 6=$ window $(27 \times 18 \mathrm{~cm})$ for observation of patient the outlet tap, resulting in a pressure of 23 mbar (equivalent to a descent of $300 \mathrm{~m}$ ) with a flow of $50 \mathrm{l} / \mathrm{min}$ in the study of 1990 . In 1991 on line registration of carbon dioxide tension in the air leaving the bag by Normocap CD 102R (AVL, Medical Instruments AG, Schaffhausen, Switzerland) allowed us to lower the air flow to $36 \mathrm{l} / \mathrm{min}$ and still keep the tension inside the bag below $1 \%$. The resulting pressure with the control treatment in 1991 was therefore 16 mbar (equivalent to a descent of $200 \mathrm{~m}$ ). This procedure still caused a noticeable pressure on the ear drum. An average pressure over both trials of about 20 mbar was applied for the control treatment. In 1990 the first seven subjects assigned to low pressure were unintentionally treated with 39 mbar (equivalent to a descent of $500 \mathrm{~m}$ ) until the inaccuracy of the built in manometer in the low pressure range was discovered. Their results were excluded from analysis, although they were not significantly different from those obtained in subjects treated with 16 or 23 mbar.

\section{ASSESSMENT OF ACUTE MOUNTAIN SICKNESS}

A clinical score for acute mountain sickness was assessed by interview and clinical examination. A score of 1 point each was given for headache, nausea, dizziness, insomnia, and facial oedema and 2 points each for headache resistant to mild analgesics taken within the previous 12 hours, nausea with vomiting, and ataxia (abnormal heel to toe walking or Romberg's sign). Headache and one additional sign or symptom were required for entering the trial.

Symptoms of acute mountain sickness were also assessed by the AMS-C score of the questionnaire of Sampson et al. ${ }^{10}$ A score of over 0.70 was shown to exclude subjects who did not report feeling ill at high altitude. ${ }^{10}$

\section{ANALYSIS}

Between groups values before treatment and changes associated with treatment were compared with analysis of variance and values after treatment with analysis of covariance by adjusting for the covariable pretreatment value with the SAS software. ${ }^{11}$ The Student Newman Keules $t$ test was applied for later testing. Contingency tables were used for comparison of drug intake between groups and $\mathrm{p}<0.05$ (two sided) was considered to indicate significance. Values are reported as means (SE).

\section{Results}

Age, days spent above $2000 \mathrm{~m}$, and hours spent at $4559 \mathrm{~m}$ before treatment as well as the intake of analgesics did not differ significantly between the treatment groups (table I). Nine subjects were smokers and 40 had ingested alcohol in moderate amounts (mostly $<30 \mathrm{~g}$ ) in the preceding 24 hours. Rales were found in only five subjects, without other clinical signs of high altitude pulmonary oedema such as dyspnoea or tachypnoea. The amount of smoking, alcohol intake, and the occurrence of rales was not significantly different between treatment groups. The clinical score, the AMS-C score of the questionnaire on symptoms, and oxygen saturation were not significantly different between these groups before treatment (table II).

During treatment with 193 mbar the median oxygen saturation was $90 \%(p<0.001)$ while oxygen saturation in the other groups remained as before treatment at about $70 \%$ (table I). The clinical score decreased significantly during treatment in all three groups while the AMS-C score was significantly lower compared with values before treatment only in the subjects exposed to $20 \mathrm{mbar}$ or to $193 \mathrm{mbar}$ (table II). The decrease in the clinical score during treatment was significantly greater with 193 mbar $(2 \cdot 7 ; 95 \%$ confi- 
TABLE I-Details of subjects, altitude exposure, and drug intake in mountaineers treated with different pressures in hyperbaric chamber or bed rest

\begin{tabular}{|c|c|c|c|c|}
\hline \multirow[b]{2}{*}{ Variable } & \multicolumn{3}{|c|}{ Treatment group } & \multirow{2}{*}{$\begin{array}{c}\mathrm{p} \\
\text { Value }\end{array}$} \\
\hline & $193 \mathrm{mbar}$ & $20 \mathrm{mbar}$ & Rest & \\
\hline No of subjects & 31 & 23 & 10 & \\
\hline No of men & 25 & 14 & 10 & $0 \cdot 15$ \\
\hline $\begin{array}{l}\text { Mean (range) age (years) } \\
\text { No (SE) of days above } 2000 \mathrm{~m}\end{array}$ & $31(19-52)$ & $30(18-47)$ & $33(18-54)$ & 0.94 \\
\hline $\begin{array}{l}\text { before treatment } \\
\text { No }(S E) \text { of hours at } 4559 \mathrm{~m}\end{array}$ & $1 \cdot 1(0 \cdot 2)$ & $1.3(0.2)$ & $2 \cdot 1(0 \cdot 3)$ & 0.25 \\
\hline $\begin{array}{l}\text { before treatment } \\
\text { No }(\%) \text { who used analgesics: }\end{array}$ & $9 \cdot 7(2 \cdot 2)$ & $4.4(0.5)$ & $6 \cdot 3(1 \cdot 7)$ & $0 \cdot 17$ \\
\hline Before treatment & $10(32)$ & $11(48)$ & $\begin{array}{l}3(30) \\
8(80)\end{array}$ & $\begin{array}{l}0.44 \\
0.45\end{array}$ \\
\hline $\begin{array}{l}\text { No }(\%) \text { who used antiemetics: } \\
\text { After treatment }\end{array}$ & $2(6)$ & $6(26)$ & $2(20)$ & $0 \cdot 13$ \\
\hline
\end{tabular}

^Kruskal-Wallis test or contingency tables.

dence interval $2 \cdot 2$ to $3 \cdot 3)$ compared with 20 mbar (1.5; 0.7 to 2.3$)$ and rest $(1.8 ; 1.1$ to $2.5 ; \mathrm{p}<0.025)$. The corresponding values for AMS-C scores were $1 \cdot 1(0 \cdot 8$ to 1.34$), 0.5(0.20$ to 0.76$)$, and $0.2(-0.27$ to 0.70 ; $\mathrm{p}<0.001)$ respectively. The clinical score immediately after treatment was significantly lower in the group treated with 193 mbar than in those treated with 20 mbar or rest alone. The differences of the AMS-C score between groups immediately after treatment were also significant $(p<0.005)$ when values were adjusted for the covariable value before treatment (table II).

During the 12 hour follow up period $58-80 \%$ of the subjects in each group took analgesics (table I) whereas the used of antiemetics was rare. The group treated with 193 mbar used fewer drugs but this was not significant. Twelve hours after treatment the clinical score was significantly lower than before treatment in all groups, and the AMS-C score was significantly lower only in the group treated with 193 mbar (table II). There were, however, no significant differences between groups for the clinical score, the AMS-C score, and oxygen saturation after 12 hours even when these variables were adjusted for values before treatment. The reduction in both scores compared with values before treatment was not significant either.

\section{Discussion}

One hour of treatment with a pressure of $193 \mathrm{mbar}$ corresponding to a descent of $2250 \mathrm{~m}$ in a portable hyperbaric chamber leads to greater relief of symptoms of acute mountain sickness immediately after treatment than control treatment or rest in a supine position. This short term beneficial effect may be attributed to improvement of oxygenation.

There was, however, no significant beneficial long

TABLE II-Mean scores (95\% confidence intervals) of acute mountain sickness and oxygen saturaton in subjects treated with different pressures in hyperbaric chamber or bed rest

\begin{tabular}{|c|c|c|c|c|}
\hline & \multicolumn{3}{|c|}{ Treatment group } & \multirow{2}{*}{$\begin{array}{c}\mathbf{p} \\
\text { Value }\end{array}$} \\
\hline & $193 \mathrm{mbar}$ & 20 mbar & Rest & \\
\hline \multicolumn{5}{|l|}{ Clinical score: } \\
\hline Before treatment & $4 \cdot 1(3.7$ to 4.5$)$ & $4 \cdot 3(3 \cdot 7$ to $4 \cdot 8)$ & $4.5(4.0$ to 5.0$)$ & 0.64 \\
\hline After treatment & $1.4(1.1$ to 1.6$) \dagger \ddagger$ & $2 \cdot 7(2.1$ to 3.4$) \dagger$ & $2.7(2.1$ to 3.3$) \dagger$ & $<0.001$ \\
\hline 12 hours after treatment & $2.5(1.8$ to 3.2$) \dagger$ & $3.1(2.4$ to 3.9$) \dagger$ & $2 \cdot 3(2 \cdot 1$ to $3 \cdot 3) \dagger$ & $0 \cdot 29$ \\
\hline \multicolumn{5}{|l|}{ AMS-C score: } \\
\hline After treatment & $0.81(0.56$ to 1.07$) \dagger$ & $1.13(0.77$ to 1.48$)$ & $1.20(0.95$ to 1.77$)$ & $<0.005$ \\
\hline 12 hours after treatment & $1.02(0.87$ to 1.31$) \dagger$ & $1.36(0.87$ to 1.86$)$ & $0.92(0.43$ to 1.41$)$ & 0.09 \\
\hline \multicolumn{5}{|l|}{ Oxygen saturation (\%): } \\
\hline Before treatment & $71(67$ to 75$)$ & $72(68$ to 76$)$ & 70 (62 to 78$)$ & 0.87 \\
\hline During treatment & $90(88$ to 91$)+t$ & $71(67$ to 75$)$ & $68(61$ to 75$)$ & $<0 \cdot($ \\
\hline 12 hours after treatment & $72(68$ to 76$)$ & 74 (70 to 77$)$ & $74(70$ to 79$) 9$ & 0.50 \\
\hline
\end{tabular}

*Analysis of variance or covariance (see methods)

$\dagger \mathrm{p}<0.01$ Compared with pretreatment values.

$\ddagger \mathrm{p}<0.01$ Compared with corresponding values of other groups.

s $<0.05$ Compared with pretreatment values.

$\| \mathrm{p}<0.001$ Compared with corresponding values of other groups. term effect which could be attributed to the hyperbaric treatment. Intake of analgesic and antiemetic drugs during the 12 hour follow up period was not significantly different between groups. Furthermore, symptom scores were not significantly different 12 hours after treatment between the groups. The amelioration of symptoms after 12 hours compared with values before predominantly reflects the influence of drugs and possibly the natural history.

In the light of the preliminary results of a recent trial performed at $4300 \mathrm{~m}$ in subjects ascending to $4800 \mathrm{~m}$ within two days it is unlikely that prolonging the treatment to 3 hours would have resulted in a better long term outcome. There was no significant difference in acute mountain sickness scores 9 hours after hyperbaric treatment between 27 subjects exposed to 220 mbar for 3 hours and 24 control subjects who remained at ambient pressure. ${ }^{12}$

The severity of acute mountain sickness correlates inversely with arterial oxygen saturation. ${ }^{513}{ }^{14}$ Breathing oxygen enriched air leads to a rapid improvement of symptoms. ${ }^{15}$ It is debatable whether hypobaria by itself is a pathogenetic factor in acute mountain sickness. ${ }^{16}$ An equal increase of oxygen saturation either by supplemental oxygen or by hyperbaric treatment is said to result in comparable improvement of symptoms. ${ }^{17}$ The beneficial short term effects of hyperbaric treatment can therefore be attributed to the increased oxygen tension inside the bag resulting in an oxygen saturation of $90 \%$ during treatment.

Treatment with 16-23 mbar, equivalent to a descent of 200 to $300 \mathrm{~m}$, did not result in a significant improvement of oxygen saturation and can thus be considered as control treatment regarding the oxygen supply. The unchanged oxygen saturation may be explained by an increase of carbon dioxide tension to slightly below $1 \%$ inside the bag $^{6}$ which prevented the expected increase of oxygen tension of about 5 mbar. As rest alone had the same effect as the control treatment it may be concluded that, firstly, the clinical improvement may be attributed to physical rest rather than to a placebo effect of the bag treatment, and, secondly, the small increase of the pressure associated with the control treatment had no additional beneficial effect. We can only speculate about the causes of amelioration of acute mountain sickness in the presence of unchanged oxygen saturation. The feeling of being taken care of might have affected the perception of symptoms. Acute mountain sickness is a very subjective illness. ${ }^{15}$ Thus control groups are essential in interventional studies evaluating different treatments of acute mountain sickness. Furthermore, despite a delay of 4-10 hours between the subjects stopping mountaineering activities and beginning treatment, there might have been an effect of rest on symptoms augmented by exhaustion. Possibly pathogenetic factors induced by exercise such as water and salt retention, ${ }^{18}{ }^{19}$ pulmonary artery hypertension, ${ }^{20}$ and desaturation ${ }^{1921}$ were favourably influenced by rest.

Our findings agree with other reports on the beneficial short term effects of treatment in portable hyperbaric chambers on acute mountain sickness. ${ }^{7-9}$ In contrast to these investigations, performed in Himalayan trekkers at altitudes of $4240 \mathrm{~m}$ or $3750 \mathrm{~m}$, we could not find any notable long term beneficial effects associated with this treatment. The discrepancy is probably due to differences in methods, acuity of ascent, and the lack of control groups in the previous studies.

Portable hyperbaric chambers present an inexhaustible light weight source of additional oxygen pressure which leads to a rapid relief of symptoms of high altitude illnesses. Single bouts of treatment, however, have no prolonged effect in most cases. Additional studies are needed to determine optimal duration and 
frequency necessary to obtain sustained improvement. Until further information is available we recommend that portable hyperbaric chambers must be used only to facilitate but not to delay descent when illness occurs at high altitude.

We thank the Sezione Varallo of the Italian Alpine Club for providing the locations in the Capanna Margherita, and the Swiss Army for transporting some of the equipment.

This study was supported by a grant from the research institute of the Swiss School of Sports, Magglingen, and by grant 3200-0092.85 from the Swiss National Science Foundation.

1 Hackett PH, Rennie D, Levine HD. The incidence, importance, and prophylaxis of acute mountain sickness. Lancet 1976;ii:1149-54.

2 Maggiorini M, Bühler B, Walter M, Oelz O. Prevalence of acute mountain ickness in the swiss alps. BM7 1990;301:853-5.

3 Hackett PH, Rennie D, Grover RF, Reeves JT. Acute mountain sickness and the edemas of high altitude: a common pathogenesis. Respir Physiol 1981;46:383-90

4 Sutton JR, Lassen N. Pathophysiology of acute mountain sickness and high altitude pulmonary oedema: an hypothesis. Bull Europ Physiopathol Respir 1979;15:1045-52.

5 Bärtsch P, Vock P, Maggiorini M, Franciolli M, Fretz C, Schobersberger W, et al. Respiratory symptoms, radiographic and physiologic correlations at high altitude. In: Sutton JR, Coates G, Remmers JE, eds. Hypoxia: the adaptions. Toronto: BC Decker Inc, 1990:241-45.

6 Gamow RI, Geer GD, Kasic JF, Smith HM. Methods of gas-balance control to be used with a portable hypertaric chamber in the treatment of high altitude be used with a portable hyperbaric chamber in the

7 Taber RL. Protocols for the use of portable hyperbaric chamber for the treatment of high altitude disorders. Fournal of Wilderness Medicine 1990; $181-92$.

8 King SJ, Greenlee RR. Successful use of the Gamow hyperbaric bag in the treatment of altitude illness at Mount Everest. fournal of Wilderness Medicin 1990;1:193-02

\section{Relationship between adult victims of assault and children at risk of abuse}

\section{Lisa Ward, Jonathan P Shepherd, Alan M Emond}

Department of Community Child Health, United Bristol Healthcare Trust, Bristol BS8 1QB Lisa Ward, senior house officer Alan M Emond, consultant community paediatrician

\section{Department of Oral} Surgery, Medicine, and Pathology, University of Wales College of Medicine, Cardiff CF4 4XY Jonathan P Shepherd, professor of oral and maxillofacial surgery

Correspondence to: Dr Emond.

BMF 1993;306:1101-2
Domestic violence is known to be linked with abuse and neglect of children, and its occurrence has been used to detect vulnerable children before abuse occurs. Surveys of victims of violence have shown a preponderance of single young men, ${ }^{2}$ who are often in fights and consume more alcohol than controls matched for age and sex. ${ }^{3}$ We investigated the extent to which adult victims of violence are members of families in which children are known to be at risk of abuse.

\section{Methods and results}

During 1986-9 we prospectively collected data from adults who attended the accident and emergency department of Bristol Royal Infirmary with injuries resulting from violence. We interviewed the patients at initial attendance and at follow up and recorded details of the assault, police involvement, the patients' alcohol

Details of adult victims of assault recorded in accident and emergency department of Bristol Royal Infirmary during 1986

\begin{tabular}{lc}
\hline & No of subjects ( $\mathbf{n}=535)$ \\
\hline Men & 456 \\
Women & 79 \\
Mean age (years) & 24 \\
(range) & $(15-80)$ \\
Ethnic group: & 493 \\
White & 19 \\
Afro-Caribbean & 5 \\
Asian & 4 \\
Other & 18 \\
Unknown & \\
Employment: & 129 \\
Manual & 183 \\
Other & 139 \\
Unemployed & 19 \\
Student & 15 \\
Housewife & \\
\hline
\end{tabular}

9 Robertson JA, Shlim DR. Treatment of moderate acute mountain sickness with pressurization in a portable hyperbaric (Gamow) bag. Journal of Wilderness Medicine 1991;2:268-73.

10 Sampson JB, Cymerman A, Burse RI, Maher JT, Rock PB. Procedures for the measurement of acute mountain sickness. Aviat Space Environ Med 1983;54:1063-73.

11 SAS Institute. SAS/STAT guide for personal computers. Version 64. Cary, ed. North Carolina: SAS Institute, 1987.

12 Herry JP, Jean D, Kayser B, Bärtsch P. Effect of a 3-hour recompression a 220 mbar on acute mountain sickness during climbing Mont-Blanc. Int 7 Sports Med 1992;13:83. (Abstract.)

13 Birmingham Medical Research Expeditionary Society Mountain Sicknes Study Group. Acetozolamide in control of acute mountain sickness. Lance $1981 ; \mathrm{i}: 180-93$.

14 Johnson TS, Rock PB. Acute mountain sickness. $N$ Engl $f$ Med 1988;319: $841-5$.

15 Bärtsch P, Baumgartner R, Waber U, Maggiorini M, Oelz O. Controlled trial of breathing $\mathrm{CO} 2$-enriched, $\mathrm{O} 2$-enriched and normal air in the treatment of acute mountain sickness. Lancet 1990;336:772-5.

16 Grover $R$ Tucker A Reeves JT. Hypobaria: an etiologic factor in acute mountain sickness. In: Lowppky JA, Riedesel ML, eds. Oxygen transpon to human tissue. New York: Elsevier, 1982:223-30.

17 Hackett PH, Roach RC, Goldberg S, Greene ER, Selland M, Wilson N, et al. A portable, fabric hyperbaric chamber for treatment of high altitude pulmonary oedema. In: Sutton JR, Coates G, Remmers JE, eds. Hypoxia: the adaptions. Toronto: BC Decker Inc, 1990:291. (Abstract.)

18 Milledge JS, Bryson EI, Catley DM, Hesp R, Luff N, Minty BD, et al. Sodium balance, fluid homeostasis and the reninaldosterone system during prolonged exercise of hill walking. Clin Sci 1982;62:595-04.

19 Bärtsch P, Maggiorini M, Schobersberger W, Shaw S, Rascher W, Girard J, et al. Enhanced exercise-induced rise of aldosterone and vasopressin preceding mountain sickness. I Appl Physiol 1991;71:136-43.

20 Reeves JT, Groves BM, Sutton JR, Wagner PD, Cymerman A, Malconian $\mathrm{MK}$, et al. Operation Everest II: preservation of cardiac function at extreme MK, et al. Operation Everest 11: prese.

21 Schoene RB, Lahiri S, Hackett PH, Peters RM, Milledge JS, Pizzo CJ, et al Relationship of hypoxic ventilatory response to exercise performance on Mount Everest. $₹$ Appl Physiol 1984;56:1478-83.

(Accepted 8 February 1993)

consumption, and their demographic and family characteristics. ${ }^{4}$ With the ethical committee's approval, we compared the names and dates of birth of the 535 adult victims of assault recorded during 1986 with data from Avon child protection register. When we found a match we took further information from the register. This lists children who are or have been at risk of abuse, their siblings, and adults closely associated with them. At the time of the study (before new guidance was issued ${ }^{5}$ ) the register's categories were physical, sexual, or emotional abuse; neglect; and grave concern.

Most of the 535 adult victims of assault were young white men injured in street fights; only $15 \%$ of the patients were women (table). Eighteen of the adults (nine men and nine women) were listed on the child protection register. This $1: 1$ ratio of men to women was significantly different from the 30:1 ratio among the adult victims overall ( $p<0.05, t$ test). There was no difference in age, employment status, or ethnic background between the victims who were on the register and those who were not. Eight of the nine women listed on the register knew their assailant: three were boyfriends, two husbands, two colleagues, and one an exhusband. Five women were assaulted by their current partner, and three of these men had convictions for violence or rape, two being schedule 1 offenders (previous convictions for child abuse).

The 18 adults listed on the register were associated with children registered under the following categories: sexual abuse (three), physical abuse (seven), grave concern (six), and both sexual and physical abuse (one). One child was not categorised. Four of these children were considered to be at risk at the time of the study. The others were no longer thought to be at risk and their files were dormant.

\section{Comment}

Although only $3.3 \%$ of the adult victims of assault were recorded on the child protection register, our results have important implications. We studied adult victims of assault who attended hospital in one year, and this represents only a small fraction of all domestic violence. ${ }^{5}$ The data suggest that mothers of children on the register are more at risk of being assaulted than 